\title{
Risk based decision making in Kaunas hydropower system during flood period
}

\author{
J. Simaityte Volskiene, J. Augutis \& E. Uspuras \\ Lithuanian Energy Institute, Lithuania
}

\begin{abstract}
The biggest hydropower system (HS) in Lithuania is situated on River Nemunas and consists of Kruonis pump storage plant and Kaunas hydropower plant. Just downstream from the system Kaunas city is situated, with a population over 0.4 million, the safety of the population is strongly dependent on the hydropower system reliability. Risk decision strategies considered using risk analysis, applied for the following system issues: before the water level reaches maximal limit, it is necessary to make risk based decisions related to the dam safety. A risk based decision making model proposes a water amount in the upper and downstream reservoirs and by numerical examples shows how decisions are dependent on different risk levels in order to decrease flood risk.

Keywords: risk based decision making, dam safety and flood management.
\end{abstract}

\section{Introduction}

The recent attempts to increase renewable energy generation and rising public awareness concerning safety and environmental issues have led to a demand for improved performance also in hydro energy and water recourses management. Decision makers have to find the best strategies for water recourses control in order to support an acceptable risk level of the systems and at the same time meet economical and environmental requirements.

The main goal of this study is to develop strategies, which would help the dam owners to accept risk based decisions during the flood period performing Kaunas hydropower reservoir control: 1) water level control; 2) water discharge control and 3) water volume in Kaunas reservoir and Kruonis artificial reservoir control. Development of decision strategies is based on qualitative risk assessment. 


\section{Kaunas hydropower system description}

The objective of the analysis is to develop strategies evaluating common risk of Kaunas hydropower plant and Kruonis pump storage power plant; hence in this study they are definable as Kaunas hydropower system, presented in Figure 1.

Construction of the Kaunas hydropower plant began in 1955. The plant has 4 turbines of $100.8 \mathrm{MW}$ total nominal power. There are three spillways operated by motors or by crane. Kaunas dam is an earth fill structure; its altitude is $48.0 \mathrm{~m}$; nominal water level $44 \mathrm{~m}$. Volume of the reservoir at nominal water level is 462 million $\mathrm{m}^{3}$ and occupies $63.5 \mathrm{~km}^{2}$.

About $26 \mathrm{~km}$ upstream of the Kaunas hydropower plant the Kruonis pump storage plant is located, with an installed capacity of $600 \mathrm{MW}$. The Kruonis pump storage plant takes water from the Kaunas reservoir of 462 million $\mathrm{m}^{3}$ to its artificial concrete reservoir with a storage volume of 49 million $\mathrm{m}^{3}$.

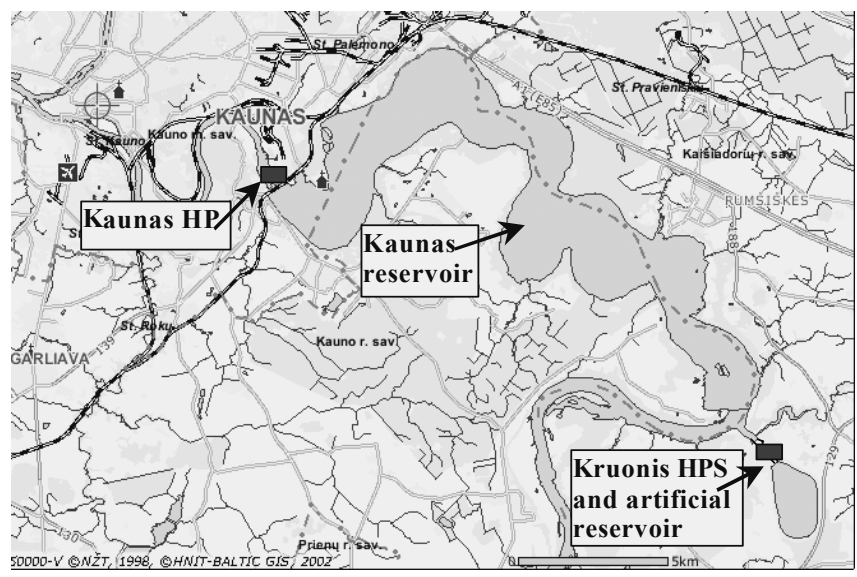

Figure 1: Kaunas hydropower system.

\section{Risk based decision making analysis}

To reach a good decision there exists two ways of thinking [1]: 1) establish an optimization model of the decision-making process and 2) see decision making as a process with formal risk and decision analyses to provide decision support, followed by informal managerial judgment and review process resulting in a decision. Figure 2 shows the basic structure of decision making process.

This paper analyses how and which dam risk analysis issues can support the decision making process. No standard procedures or methods exist to determine comprehensively the failure risk of a dam as a whole. The application of risk analysis to dams comes with its own distinct set of problems. Some authors [2] have described the sequential steps that comprise the assessment of dam safety using risk analysis and the primary steps in most works consist of: risk identification; risk estimation; risk reduction and risk acceptance. 


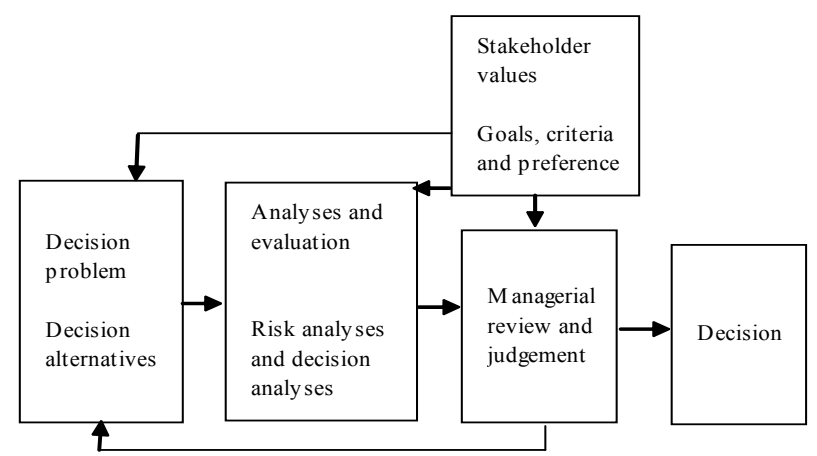

Figure 2: $\quad$ Basic structure of the decision making process.

Risk estimation entails the assignment of estimated probabilities to the events and responses identified under risk identification. Risk magnitude $R$ is defined as the product of the assessed probabilities:

$$
R=\Sigma\left(P_{\text {Load }} \times P_{F / \text { Load }}\right)
$$

where $\mathrm{P}_{\mathrm{Load}}$ - probability of load condition; $\mathrm{P}_{\mathrm{F} / \mathrm{Load}}$ - probability of failure given load condition.

Risk reduction is if the calculated risk of the existing system is too high, alternatives are proposed to reduce the risk of failure. Risk acceptance defines the level of residual risk that will be accepted for the affected community.

\section{Flood prognosis model}

Flood event is the one of most important factors causing dam failure and herewith the biggest consequences for the population. In the present study a flood probabilistic analysis model was applied, which produces extreme flood probabilities used for dam probabilistic risk analysis, as event tree input. The second model was developed for decision making process when it is necessary to decide which actions have to be performed in order to assure safety of the dam.

\subsection{Probabilistic analysis}

The study of extreme hydrologic event involves the selection of a sequence of the largest observations from sets of data. Hence the annual maximum peak flows has to be analysed and the probabilities of significant magnitude flood events has to be evaluated. Since these observations are located in the extreme tail of the probability distribution of all observations from which they are drawn, so their probability distribution is different from that of the parent population. In this study the distribution of extreme values type I is used [3]:

$$
F(x)=\exp \left[-\exp \left(-\frac{x-\mu}{\sigma}\right)\right], \quad-\infty \leq x \leq \infty .
$$

where the parameters are defined as $\sigma=\sqrt{6} s / \pi$ and $\mu=\bar{x}-0.5772 \sigma$. 
The hydrologic load is a continuous random variable and event tree analysis is more conductive to inputs of discrete variables. Therefore probability of occurrence of different loading ranges was calculated from the cumulative distribution function as follows:

$$
P(Q 1<q<Q 2)=F(Q 2)-F(Q 1)
$$

\subsection{Real time flood forecast}

The principle of present forecast model is statistical analysis of historical spring flood, which exceed base level. When the individual flood has its first day flow measure, the model analyses historical floods and attributes the special weight coefficients for the each flood flows and than the future flood flows are calculated. Having the second day flood flow data, the coefficients are recalculated and forecast is corrected. Hereby the flood prognosis is performed as long as flood lasts. The forecast flood values are calculated according the formula:

$$
p_{j}=\sum_{i=1}^{n} q_{i j} a_{i}, j=1 \ldots k .
$$

where $a_{i}$ - the weight coefficient; $q_{i j}-i^{t h}$ flood $j^{\text {th }}$ day flow.

Performing flood flow prognosis it is necessary to develop a reasonable coefficient system. Using Bayesian approach was developed model for update coefficients $a$, when prior $a$ distribution is determined. Model is developed in reference [4].

\section{Risk analysis of Kaunas HS modelling results}

\subsection{Factors contributing the failure of Kaunas HS}

The accident which would bring huge hazard to Kaunas city and other downstream areas is Kaunas dam failure during a flood period. There were identified and analysed the following initiating events for KHP: 1) dam body ageing and internal erosion; 2) Kruonis HPS artificial reservoir brake; 3) extreme inflow to reservoir.

\subsubsection{Dam body ageing and artificial reservoir break}

The evaluation of the dam body ageing and internal erosion requires a monitoring data and is a complex analysis of many factors. Present study limits on failure analysis of water discharge equipment. Evaluation of failure of spillways and gates operation is based on equipment failure statistics, on judgmental experience and on generic statistics [5]. The list of analysed equipment and their failure probabilities used in risk analysis model are presented in Table 1.

After Kruonis HPS operation the big debates started about the plant impact to reservoir level fluctuations and its potential hazard to the Kaunas dam. In order to evaluate possible Kruonis HPS artificial reservoir water flow to the Kaunas reservoir, the laboratory of Hydrology of Lithuanian Energy Institute [6] created 
an imitative model. Under the normal conditions a crash of Kruonis reservoir would not cause any harm to Kaunas dam, but during the floods, when water level is more than $45.6 \mathrm{~m}$, the additional water amount could additionally load water-development works and cause overtopping or even dam crash.

Table 1: $\quad$ Probabilities of dam operational elements.

\begin{tabular}{|c|c|}
\hline Description & Probability \\
\hline Emergency power failure & $3.0 \mathrm{E}-03$ \\
\hline Offsite power failure & $1.0 \mathrm{E}-03$ \\
\hline Gates drive failure & $1.0 \mathrm{E}-04$ \\
\hline Main crane failure & $3.0 \mathrm{E}-04$ \\
\hline Auxiliary crane failure & $3.0 \mathrm{E}-03$ \\
\hline One gate failure & $1.0 \mathrm{E}-02$ \\
\hline
\end{tabular}

\subsubsection{Kaunas reservoir inflow analysis}

Everyday flow data from Nemunas upstream measurement stations from period of 1920-2001was analysed. Average flooding dates in River Nemunas are from 6 March to 9 May with maximum flow on 24-30 March. Number of 82 spring maximal flows was fixed (Figure 3), which mean value is $953 \mathrm{~m}^{3} / \mathrm{s}$, and the maximal value $3450 \mathrm{~m}^{3} / \mathrm{s}$.

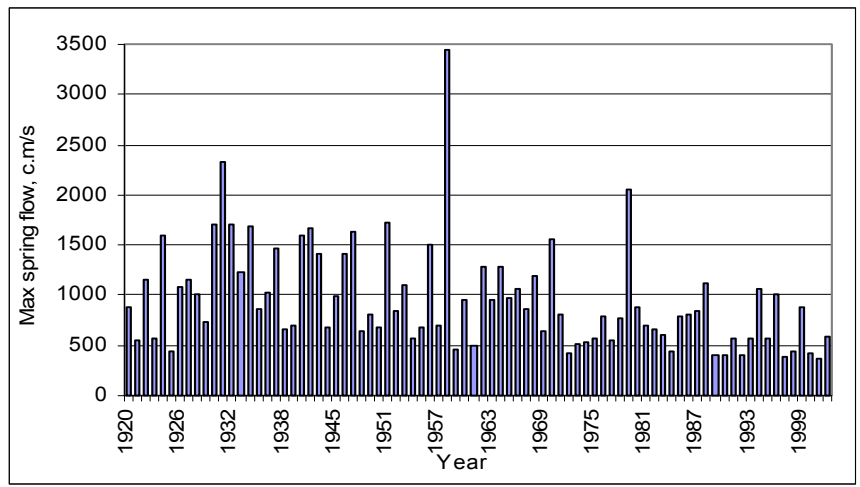

Figure 3: Nemunas River maximal spring flow data.

Performing Kaunas hydropower system risk assessment it is important to analyse of which magnitude flow flood can bring potential danger. The nominal water level to the Kaunas dam is $44 \mathrm{~m}$, and Reservoir management rules [7] let vary it from 43.1 till 44.4 . The minimal water level $-40-\mathrm{m}$ is allowed in the beginning of the spring, when big flood is expected. If the flood occurs, the maximal water level can reach $45.6 \mathrm{~m}$, which Rules indicate as maximal acceptable water level.

There were performed simple calculations of water level fluctuations under Kruonis reservoir crash. In such case extra amount of 48 million $\mathrm{m}^{3}$ would fill Kaunas reservoir, and water level near the Kaunas dam would increase by about 
$1 \mathrm{~m}$. The similar results were calculated using dynamic model [6]. Modelling water level fluctuations the flood volume was calculated under the equation:

$$
Q_{m}=\sum_{k \in\left\{M_{m}\right\}} \theta\left(X\left(t_{k}\right)-v\right) X\left(t_{k}\right) T(k) .
$$

where $Q_{m}$ - flood volume, $T(k)-k^{\text {th }}$ flood duration, $v$ - critical flow, $M_{m}$ - set of extreme spring foods, $\theta$ - Havside's function. Water level under the certain reservoir flood volume was calculated according equation:

$$
H\left(t_{k}\right)=\alpha \log Q\left(t_{k}\right)+\beta \text {. }
$$

where $\alpha$ and $\beta$ are approximated nonlinear function parameters, estimated from data: $\alpha=7.24, \beta=0.08$.

Table 2 presents the flow magnitude when the top of the dam $(48 \mathrm{~m})$ is reached after 2-3 days under various scenarios, if no action is taken. Water levels in the first column are initial levels at the beginning of flood.

Table 2: $\quad$ Critical flood flow.

\begin{tabular}{|c|c|c|c|c|}
\hline \multirow{2}{*}{$\begin{array}{c}\text { Initial water } \\
\text { level, } \mathrm{m}\end{array}$} & \multicolumn{4}{|c|}{ Number of open gates } \\
\cline { 2 - 5 } & 0 & 1 & 2 & 3 \\
\hline 40 & 900 & 2500 & 3500 & 4500 \\
\hline 44 & 900 & 2100 & 3100 & 4500 \\
\hline 45.6 & 500 & 1500 & 3100 & 4300 \\
\hline
\end{tabular}

To evaluate extreme flow probabilities, six different loading ranges were selected for the case study. The lowest, $0-500 \mathrm{~m}^{3} / \mathrm{s}$ represents the condition which is not considered as a "flood", but its analysis useful for comparison with other loading conditions. Other ranges approximately represent flow of the different return periods $-10,100,1000,10000$ and 100000 years floods. Using method presented in section 4.1 and goodness-of-fit tests, extreme values probability distribution was accepted for extreme flood data. Estimated probabilities are presented in Table 3.

Table 3: $\quad$ Probability of occurrence of flow ranges.

\begin{tabular}{|c|c|}
\hline Flow, $\mathrm{m}^{3} / \mathrm{s}$ & Probability \\
\hline $0-500$ & $1.75 \mathrm{E}-01$ \\
\hline $500-1600$ & $7.16 \mathrm{E}-01$ \\
\hline $1600-2600$ & $9.73 \mathrm{E}-02$ \\
\hline $2600-3600$ & $8.59 \mathrm{E}-03$ \\
\hline $3600-4600$ & $7.21 \mathrm{E}-04$ \\
\hline$>4600$ & $6.58 \mathrm{E}-05$ \\
\hline
\end{tabular}

\subsection{Real time flood forecast}

As the decision making process depends on real time situations, it is necessary to have methodology for flood forecast in real time basis. Using the methodology developed in section 4.2, real time forecast model was applied to River Nemunas 
historical foods flows. Figure 4 presents the example of flood forecast, when flood flow of the first day is measured, then calculated forecast of the 2 days flow measures and so on, until flood reaches its peak.

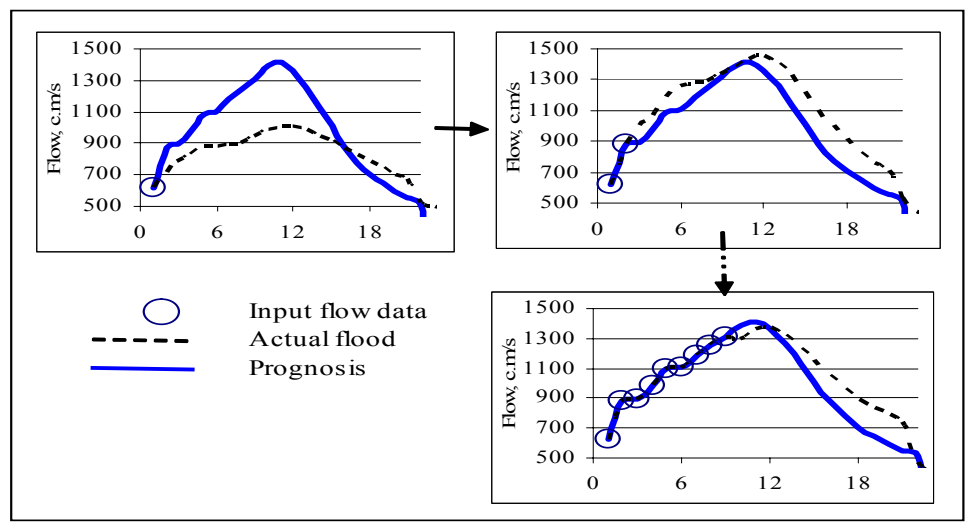

Figure 4: $\quad$ Scheme of real time flood forecast.

\subsection{Risk evaluation}

Performing risk analysis using event trees the following functional events were analysed: 1) failure to observe and act; 2) gates drive failure; 3) gates state; 4) gates fail; 5) gates blocked by debris. For analysing the causes of failure of safety barriers fault trees were used.

Dam overtopping probabilities were calculated for several scenarios, which include the initial water level to the dam and the magnitude of the inflow to the reservoir. Dam overtopping probabilities under various scenarios calculation results are presented in Table 4. Using eqn (1) the general dam overtopping probability was estimated $-5.4 \mathrm{E}-04$.

Table 4: $\quad$ Event tree analysis calculation results.

\begin{tabular}{|c|c|c|c|}
\hline Flow. $\mathrm{m} 3 / \mathrm{s}$ & 40 & 44 & 45.6 \\
\hline $0-500$ & $1.29 \mathrm{E}-05$ & $1.29 \mathrm{E}-05$ & $3.05 \mathrm{E}-05$ \\
\hline $500-1600$ & $1.25 \mathrm{E}-04$ & $1.25 \mathrm{E}-04$ & $1.38 \mathrm{E}-04$ \\
\hline $1600-2600$ & $1.69 \mathrm{E}-05$ & $1.69 \mathrm{E}-05$ & $4.96 \mathrm{E}-05$ \\
\hline $2600-3600$ & $1.31 \mathrm{E}-05$ & $4.90 \mathrm{E}-04$ & $4.90 \mathrm{E}-04$ \\
\hline $3600-4600$ & $1.21 \mathrm{E}-05$ & $3.50 \mathrm{E}-04$ & $3.50 \mathrm{E}-04$ \\
\hline$>4600$ & $9.00 \mathrm{E}-06$ & $6.58 \mathrm{E}-05$ & $6.58 \mathrm{E}-05$ \\
\hline
\end{tabular}

\section{Decision making strategies development}

Risk assessment is the process of deciding whether existing risk are tolerable and present risk control measures are adequate and if not, whether alternative risk control measures are required. The main risk measure in this study expresses general dam overtopping probability. 


\subsection{Water level and flow discharge control strategy}

Three different levels probabilities were assumed - that in the beginning of spring $40 \mathrm{~m}$ water level probability is $6.0 \mathrm{E}-01,44 \mathrm{~m}$ is $3.0 \mathrm{E}-01$ and 45.6 is $1.0 \mathrm{E}-$ 01 . In order to minimize dam overtopping risk level, the decision concerning initial water level has to be assumed. If there would be requirement water level at every spring beginning to decrease until minimal, the level frequency could be assumed higher. Let us assume that minimal water level frequency in the beginning of the spring is assumed $7.0 \mathrm{E}-01,8.0 \mathrm{E}-01$ or $9.0 \mathrm{E}-01$, respectively dam overtopping probability would decrease $1.2,1.5$ and 2 times.

Decision making strategy also has to involve the flow discharge control thorough the Kaunas dam. The event tree analysis in the previous studies [8] revealed that general overtopping probability of Kaunas dam is sensitive on flow discharge. For that reason the very detailed decision making process has to be developed which guides the water discharge control and at the same time minimizes dam failure risk level. One of the options is flood forecast analysis and action plans development in real time bases.

Illustrative example of risk based decision making process application can be presented with the most extreme historical flood which occurred in 1958, its peak reached $3450 \mathrm{~m}^{3} / \mathrm{s}$ and duration was 41 day. Let us assume the first day flood flow is measured. Using real time flood forecast model (section 4.2), the flood flow forecast was calculated. Figure 5 presents the forecast results and real flood measures for the first eight flood days.

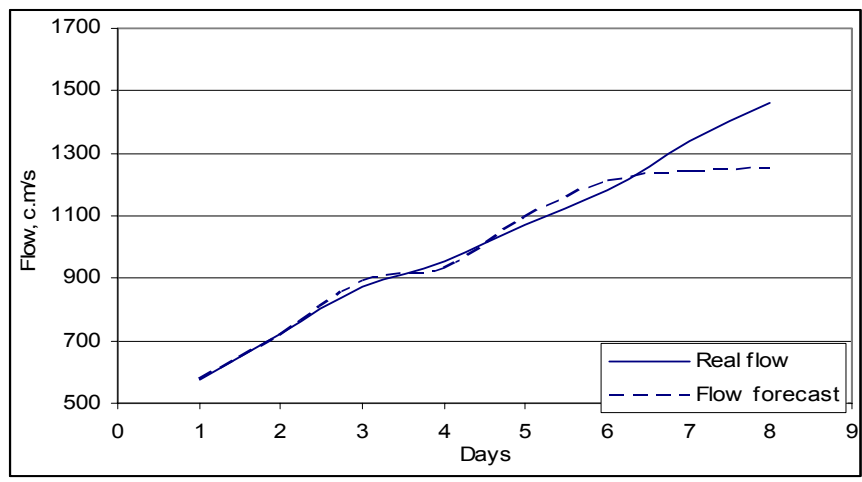

Figure 5: Real flood and its forecast of the first 8 days.

Let us assume that the water level is $40 \mathrm{~m}$ and the number of opened gates is 0 . In such situation, the critical water level 45.6 would be reached after 4 days, and the top of the dam - in 7 days, if no action would be taken. In case of Kruonis artificial reservoir crash 45.6 water level would be reached after 3 days and $48 \mathrm{~m}$ in 6 days.

Figure 6 presents water level reaching the critical water level $(45.6 \mathrm{~m})$ and the top of the dam $(48 \mathrm{~m})$ under 3 scenarios: "no opened gates", "1 gate is opened" and "2 gates are opened". The solid curve in the figure shows the water level, 
which is controlled, i.e. that using flood forecast results and risk analysis issues, situation was valued and water discharge thorough the dam managed - the critical water level, $45.6 \mathrm{~m}$, was exceeded for 3 days and only $15-20 \mathrm{~cm}$.

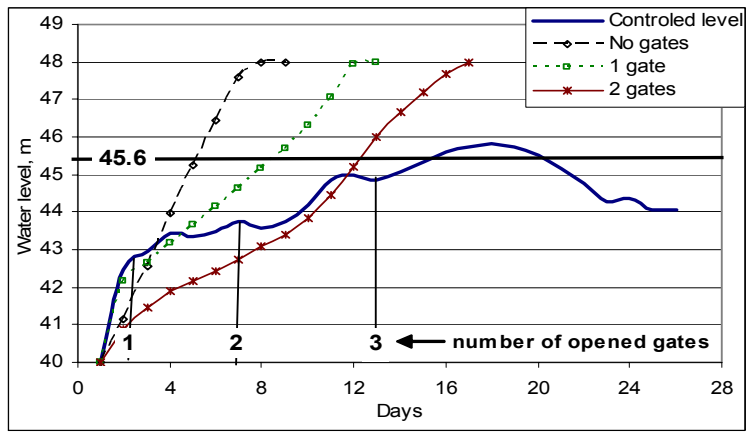

Figure 6: Flood control example

\subsection{Kruonis artificial reservoir volume control strategy}

Water level analysis results, of the scenario when gates are not opened during the flood event, are presented in Figure 7. The results show how changes water level under different scenarios, how soon it reaches maximal acceptable $45.6 \mathrm{~m}$ water level and how soon it reaches the top of the dam $(48 \mathrm{~m})$. Dotted lines presents water level increasing scenario under a Kruonis reservoir crash, when an extra amount of water flows to Kaunas reservoir. The analysis reveals that difference between the situations exists and decision about Kruonis reservoir water volume has to be taken in two different directions. The first option is Kruonis artificial reservoir water amount release in the beginning of the spring what decreases artificial reservoir failure chance, and herewith decreases Kaunas dam overtopping risk. The following option: empty Kruonis reservoir could accept 48 million $\mathrm{m}^{3}$ and to decrease water level in Kaunas reservoir. This action could be performed in very extreme situations, but at the same time with a big responsibility in decision making process.

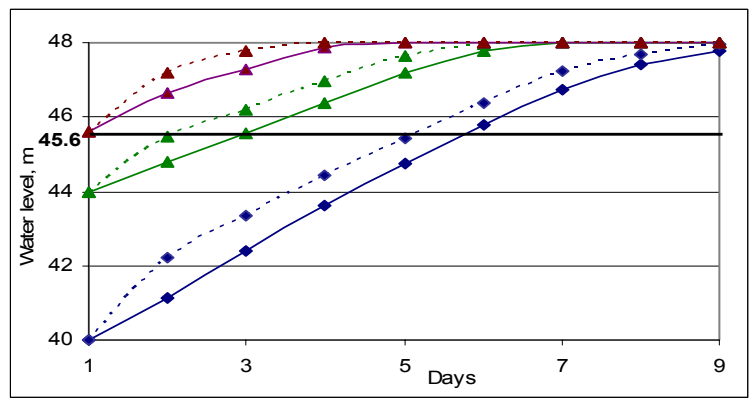

Figure 7: Water level under scenario "No gates open". 


\section{Conclusions}

1. The main risk measure in this study expresses general dam overtopping probability, which was estimated as $5.4 \mathrm{E}-04$ and is comparable with foreign countries experience.

2. The estimated probabilities in this work were assumed as risk measures which support decision making. The risk based decision making process strategies and recommendations were developed for water level and discharge control, and Kruonis HSP reservoir volume control:

a) Water level in the beginning of the spring has to be decreased until $40 \mathrm{~m}$. This reclamation would decrease probability of artificial reservoir break, therewith decrease general dam overtopping risk level. As the overtopping depends on discharge thorough the gates, their proper operation has to be considered. The illustrative example presented how risk based decision process helps to make proper actions during the flood period.

b) Kruonis artificial reservoir crash impact was analyzed thorough water level fluctuations to the Kaunas dam. The recommendation was affirmed, that Kruonis artificial reservoir in the beginning of the spring has to keep to the minimal water volume, in order to decrease dam overtopping risk level. The other option is that in extreme situations it also could assesses 48 million $\mathrm{m}^{3}$ of water amount from Kaunas reservoir and to decrease critical water level to the dam.

\section{References}

[1] Aven T., Foundations of Risk analysis, John Wiley \& Sons, Ltd., ISBN 0471-49548-4, 2003, $190 \mathrm{p}$.

[2] Graham, P. Risk analysis for the assessment and management of dam safety, $\mathrm{PhD}$ thesis, Kungl Tekniska Hogskolan, 1995, p. 25.

[3] Kotz S., Balakrishnan N., Johnson N., Continuous multivariate distributions, Models and applications, John Wiley \& Sons, Inc. USA, 2000, P. 621-659.

[4] Simaityte Volskiene J. Maximal floods forecast of the Nemunas River (in Lithuanian), ISSN 0235 - 7208, Energetika, Nr.1, 2005, P. 34-39.

[5] Simaityte Volskiene J., Uspuras E., Augutis J. Flood Forecast Model and Probabilistic Analysis, Proceed. of the 7th Intern. Conf. on Probabilistic Safety Assessment and Management, Berlin, Germany 14-18 June 2004. Springer-Verlag. ISBN 1-85233-827-X, 2004, P. 3079-3085.

[6] Gailiusis B., Kriauciuniene J., Rimaviciute E., Modelling the Effect of the Hydroelectric Pumped Storage Plant on Hydrodynamic Regime of the Kaunas Reservoir in Lithuania, Nordic Hydrology, 34 (5), 2003, P. 507-518.

[7] Kaunas HP reservoir management and maintenance rules (in Lithuanian), Lithuanian Energy Institute report, No. 33-372.3.3, 2003, 24 p.

[8] Simaityte Volskiene J., Augutis J., Uspuras E., Kriauciunene J., Risk Analysis of Kaunas Hydropower System, Proceed. of the 4th on Computer Simulation in Risk Analysis and Hazard Mitigation, Rhodes, Greece, 27-29 September 2004., ISBN 1-85312-736-1, P. 554-561. 